\title{
Agent-service Approach for Development of Intelligent Decision-making Support Systems
}

\author{
Aleksei G. Massel \\ Melentiev Energy Systems Institute \\ of Siberian Branch of the Russian \\ Academy of Sciences \\ Irkutsk, Russia \\ amassel@isem.irk.ru
}

\author{
Vasili I. Galperov \\ Melentiev Energy Systems Institute \\ of Siberian Branch of the Russian \\ Academy of Sciences \\ Irkutsk, Russia \\ galperov@gmail.com
}

\author{
Vladimir R. Kuzmin \\ Melentiev Energy Systems Institute \\ of Siberian Branch of the Russian \\ Academy of Sciences \\ Irkutsk, Russia \\ rulisp@ vigo.su
}

\begin{abstract}
This article deals with usage of agentservice approach for development of intelligent decisionmaking support systems (IDSS). Concepts of agent and multi-agent systems are being considered, and description of agent-service approach is given. Detailed description of IDSS "Situation polygon" is provided. This description includes process of development of IDSS with the help of agent-service approach, list of system's agents and example of a user's interaction with the system. Architecture of the system is also provided.
\end{abstract}

Keywords - agent-service approach, multi-agent systems, intelligent decision-making support systems, situational management.

\section{INTRODUCTION}

Currently, the concept of intelligent energy systems is spreading in Russia [1, 2]. Also, since 2017, the program of digital transformation of energy is being considered as a part of the program "Digital economy" $[3,4]$.

However, implementation of this concept, requires, on the one hand - development and utilization of modern information technologies for management of technological infrastructure, and, on the other hand modernization of the infrastructure itself. Infrastructure modernization is tightly bond with strategic decision-making for energy sector development, and requires, in turn, intellectualization of tools for support of these decisions.

Team, represented by authors, proposed an approach, based on concept of situational management. Main methods of situational management are situational analysis and situational modelling. For implementation of those methods, it is proposed to utilize authors' methods of semantic modelling (ontological, cognitive, event and probabilistic (based on Bayesian trust network)) [5]. Tools for support those types of modelling (OntoMap, CogMap, EventMap and BayNet libraries) were integrated into intelligent IT-environment, and this environment served as a prototype for the next version intelligent decision-making support system "Situation polygon". Due to the fact, that IDSS is using different types of semantic modelling, it was offered to implement it as a multi-agent system.
Multi-agent system (MAS) appeared at the intersection of artificial intelligence and the systems theory. On the one hand, this is open, active, evolving system, with the main attention paid to the processes of agents' interactions as a reason of creation of a system with new properties. On the other hand, often, MAS are created as an integration of separate systems, which are based on knowledge [6].

Multi-agent system can also be defined as a network of asynchronous objects, working together to solve a problem, that agent can't solve alone. MAS is a set of decentralized cooperating elements, called agents, and each agent works autonomously [7]. MAS, where agents show significant intelligence features and autonomy, are of interest. At the last several years, MAS technologies found applications in many distributed systems, such as distributes processing of information and distributed scientific computations.

In this article considers usage possibility of agentservice approach for development of intelligent decision-making support system "Situation polygon".

\section{AGENT-SERVICE APPROACH.}

Authors think, that it is necessary to provide a mathematical description of a methodical approach for the construction of multi-agent systems, before providing a description of usage of agent-service approach.

The system is being created with a specific goal $G$, which must be clearly defined before start of development. This goal will be reached through accomplishing a set of tasks, both simple and complex, and these tasks can be divided into separate subtasks. It is necessary to define a set of all tasks $\{T\}$, and system must be able to solve them. Set of tasks will define a function set of the future system $\{F\}$. System's functions are divided between agents $\{A\}$ in such a way, that each agent solves its own task, or a part of larger task. So, it is required to make a chain of mappings: $G \rightarrow\{T\} \rightarrow\{F\} \rightarrow\{A\}$.

But actions must be taken in a specific order and part of tasks may be solved in a different way, so it is required to define an order of agents' call $\left\{P_{A}\right\}$. Using this order and agent set in the system, it is necessary to 
generate a set of agent scenarios $\left\{S_{A}\right\}$, for which it is required to create event models describing these scenarios $\left\{E_{S}\right\}$. To speed up MAS development, it is advisable to use basic software components for agents $\left\{C_{B}\right\}$. So, a model of multiagent system can be represented as:

$$
M_{M A S}=\left(A, P_{A}, S_{A}, E_{S}, C_{B}\right),
$$

where $A$ - set of agents, $P_{A}$ - agents' call order, $S_{A}$ - set of agents' scenarios, $E_{S}-$ set of event models, $C_{B}$ - set of basic components.

Based on this mathematical description, Galperov V.I. proposed a methodical approach for creating typical multi-agent systems. Basis of this approach is the method of design and implementation of typical multiagent system (MAS), which was implemented as a method. Full description of this method was given in [8], there will be listed only main steps:

- Description of the future system, based on the specifics of solved task, that includes: determination of a goal of MAS creation, determination of set of tasks $\{T\}$, determination of set of MAS functions $\{F\}$, determination of a list of agents $\{A\}$ based on system's functions and development of MAS basic components, development of MAS basic components $\left\{C_{B}\right\}$.

- Development of agents' scenarios: determination of order of agents' call $\left\{P_{A}\right\}$, development of scenarios of agent calls $\left\{S_{A}\right\}$, description of scenarios in the form of event models $\left\{E_{S}\right\}$

- Development of MAS architecture

- Designing of MAS

- Implementation of MAS

Agent-service approach to development intelligent decision-making support "Situation polygon" is proposed due to following reasons:

- Full situation description requires creation of usage scenarios of different semantic and mathematical modelling tools

- Application of agent-service approach makes it relatively easy to add new modelling tools to the "Situation polygon"

- Some types of modelling require large and complicated calculations, which can be performed simultaneously. Agent-service approach allows to parallelize tasks and, by that, reduce calculation time

\section{USAGE OF AGENT-SERVICE APPROACH FOR DEVELOPMENT OF INTELLIGENT DECISION-MAKING SUPPORT SYSTEM "SITUATION POLYGON"}

Because of many situations, which have uncertainty factors, and appear while making a strategic decision, the team, represented by the authors, uses two-level technology. Lower level is the level of quantitative estimation of a situation. Upper level represents the level of qualitative analysis, which is made with the help of semantic modelling tools. In general, semantic model is a model, representing concepts of subject domain and relations between them. Usually, ontologies, infological data models ("entity-relationship" model), semantic networks are referred to them. In papers of the mentioned team, ontological, cognitive, event and probabilistic (Bayesian network of trust based) models are being referred to semantic modelling.

Authors propose to consider semantic modelling as a one of the directions of semiotic modelling, in which the graphic representation of the developed models predominates, with elements of cognitive graphics. In order to implement the proposed approach, scientific prototype of intelligent decision-making support system "Situation polygon" is being developing [9]. Now, it'll be shown how to develop this system considering the approach from the previous chapter.

The main goal of creation of this system is to provide support of decision-making for an expert (or decision-maker). As for a set of tasks $\{T\}$ we may define this list:

- Support of semantic modelling tools

- To provide an ability to convert one type of semantic model to another (e.g. from ontology to cognitive map)

- Work with knowledge bases, which includes both content and subsequent work with it searching, editing knowledge, etc.

- Ability to visualize results, obtained from semantic modelling tools, using Geocomponent

- Work with database to provide the system's functioning. Database stores system's configurations, users' data and some models

To implement this set of tasks, team, represented, by the authors, develops Contingency Management Language (CML) [], which appears to be the one of the main components of the system. CML can be divided into two parts:

- Tools for knowledge manipulation $M$ (support of representations)

- Tools for knowledge description $D$ (description of situations, scenarios, control actions)

Fig. 1 displays CML's metaontology.

As it was said, CML is the one of the main components of the system, and it provides function of knowledge description, interface function and function of components integration.

In accordance with the set of tasks, described above, the system must have a set of functions, which allows, to solve these tasks. From this, we can conclude that the following list of agents is required: 


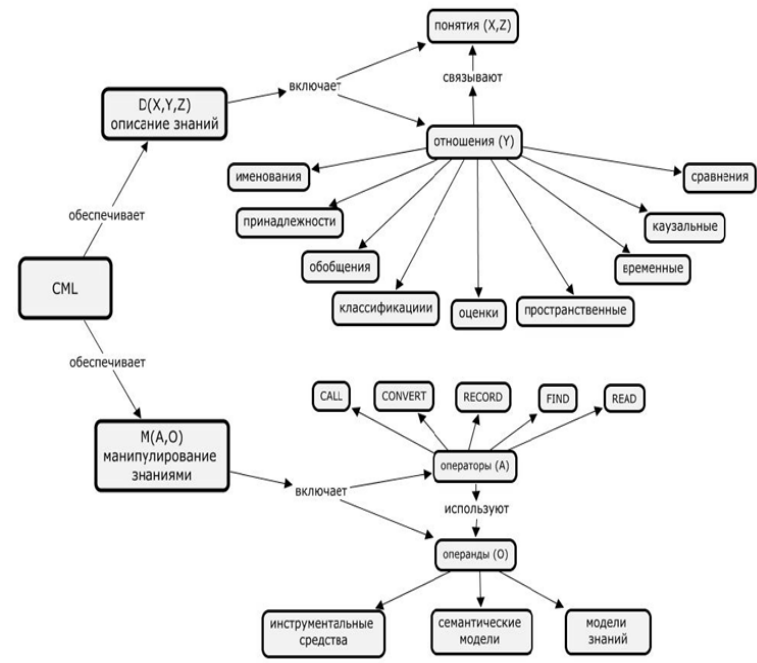

Fig. 1. Metaontology of CML

- Main agent-coordinator - controls other coordinating agents, contains agent scenarios, which are used for call order of agentcoordinators, provides user's actions control $\left\{A_{\text {COORD }}\right\}$

- Agent-coordinator of database - provides access to the database $\left\{A_{D B}\right\}$

- Agent-coordinator of knowledge base provides access to the knowledge base $\left\{A_{K B}\right\}$

- Agent-coordinator of the semantic modelling tools - controls agents, which responsible for work of semantic modelling tools $\left\{A_{S M}\right\}$. Every tool is an agent too.

- Agent-coordinator of mathematical modelling tools - controls agents, which responsible for work of mathematical modelling tools $\left\{A_{M M}\right\}$. Every tool is an agent too.

- Agent-coordinator of visualization tools and Geocomponent - allow to visualize obtained results as an ontology, cognitive map or by using map services $\left\{A_{\text {GEOVIS }}\right\}$

Set of basic components $\left\{C_{B}\right\}$ includes these elements:

- Semantic modelling tools - OntoMap $\left(C_{O N T}\right)$, CogMap $\left(C_{C O G}\right)$, EventMap $\left(C_{E V E N T}\right)$, BayNet $\left(C_{B N}\right)$

- Expert system "Advice" that provides creation and usage of knowledge base

- Repositary, that stores semantic models and allow to work with them $\left(C_{R E P}\right)$

- Database - stores all system's information $\left(\mathrm{C}_{\mathrm{DB}}\right)$
- Geocomponent - displays obtained results using map services $\left(C_{G E O}\right)$

Considering methodic from the previous chapter and lists of agents and components, architecture of intelligent decision-making support system "Situation polygon" can be represented as follows (fig. 2).

Fig. 3 displays example of a workflow for user. List of processes is the following:

- $A_{S M}$ - work of agent-coordinator of semantic modelling tools. It may finish the work if desired result is achieved, or call next tool of semantic modelling if it is required

- $A_{O N T}$ - work of agent, responsible for ontological modelling

- $A_{C O G}$ - work of agent, responsible for cognitive modelling

- $A_{C O O R D}$ - work of main agent-coordinator

- $A_{M M}$ - work of agent-coordinator of mathematical modelling tools

- $A_{\text {INTEK }}$ - work of agent, that is responsible for software complex INTEK

List of events is the following:

- $S_{\text {START - user starts his work with the system }}$ and calls tools of semantic modelling

- $S_{\text {ONT_INIT }}$ - initialization of ontology modelling tool - CML (CALL, $\left.C_{O N T}\right)$. If required, existing ontology will be loaded from the knowledge base

- $S_{\text {ONT FINISH }}$ - end of work with ontology modelling tool. Results will be stored in the knowledge base with the help of command $C M L$ (RECORD, ontology), where ontology is the model, built on current step.

- $S_{C O G_{-} I N I T}$ - initialization of modelling tool for cognitive maps - CML $\left(C A L L, C_{C O G}\right)$. If required, can obtain results from the previous step, by calling CML (CONVERT, ontology), where ontology is the model, built on previous step.

- $S_{\text {COG_FINISH }}$ - end of work with cognitive modelling tool. Results will be stored in the knowledge base, control will be returned to $A_{S M}$

- $S_{\text {SEM_FINISH }}$ - end of work with semantic modelling tools, control will be returned to the $A_{S M}$

- $S_{M M_{-} I N I T}$ - initialization of mathematical modelling tools

- $S_{M M \_I N T E K}$ - initialization of software complex INTEK

- Res - work of system is finished 


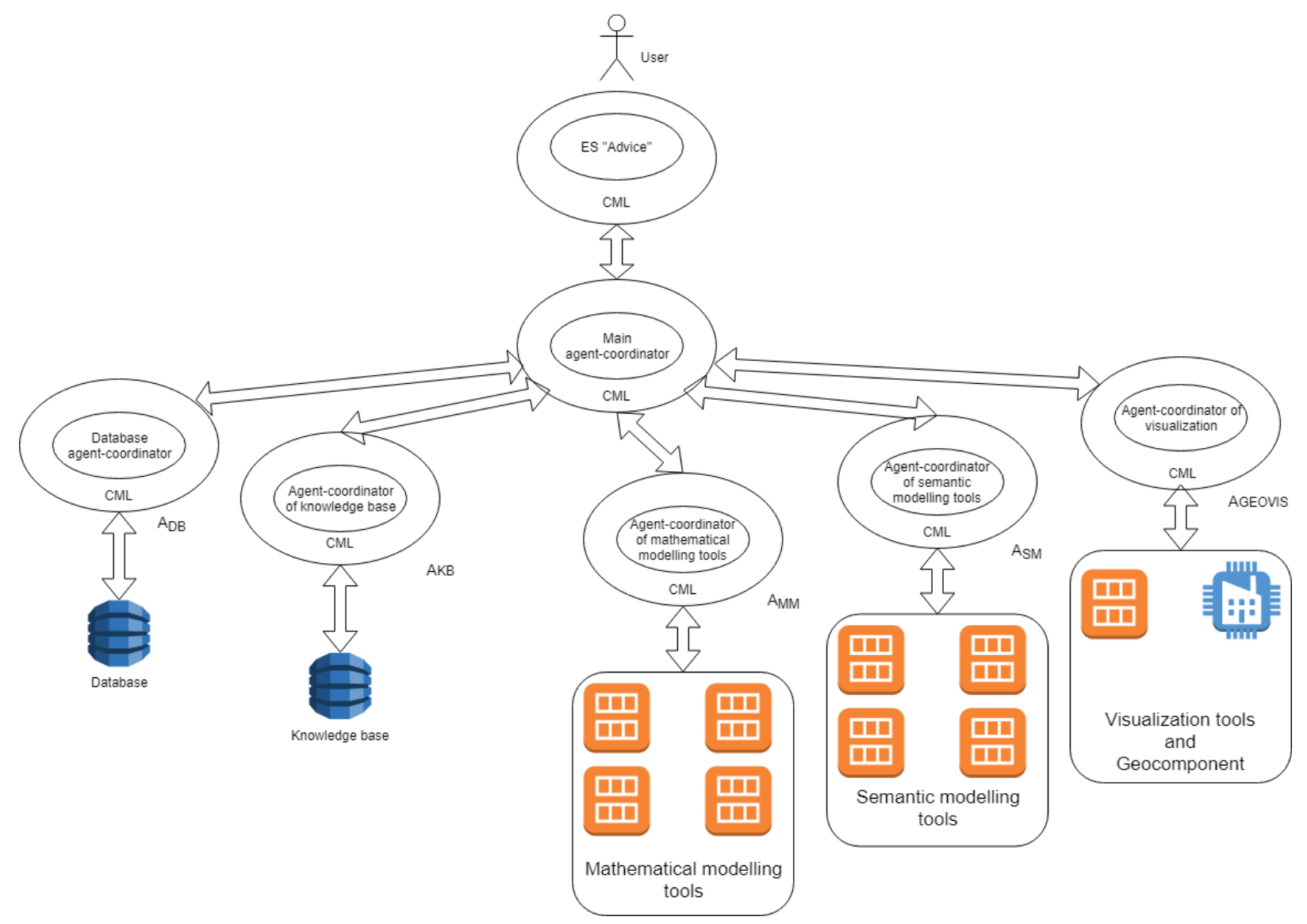

Fig. 2. Architecture of "Situation polygon"

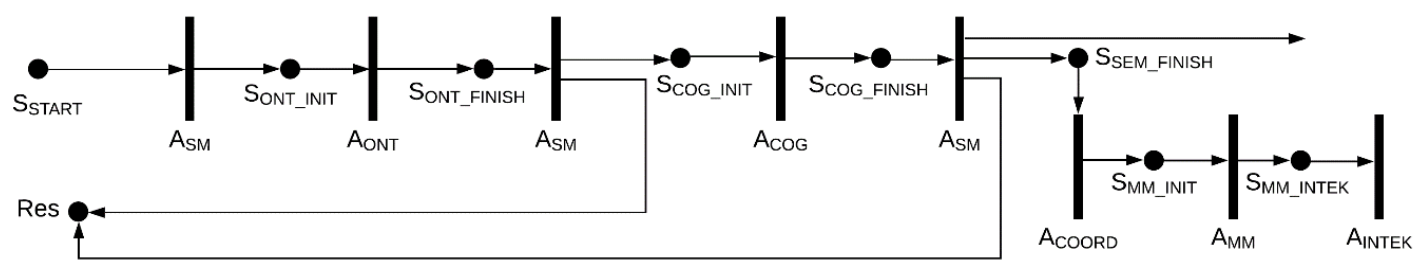

Fig. 3. Example of a workflow in the system

\section{CONCLUSIONS}

In this article, author's methodic approach for development of typical multi-agent systems (MAS) was considered. This approach is based on the method of designing and implementation of typical MAS and it was implemented as a methodic. Detailed description of intelligent decision-making support system "Situation polygon" is provided and its structure was pictured. Also, this article considers typical workflow for a user of this system.

\section{ACKNOWLEDGMENT}

Authors thank the staff of the Laboratory of Information Technologies located at ISEM SB RAS. Discussions of scientific problems have contributed a lot to formulating the results presented in this article. This work was partially supported by RFBR grants
№19-07-00351, №18-07-00714, 18-37-00271, 18-5781001, 17-07-01341

\section{REFERENCES}

[1] Momoh J., Smart Grid: Fundamentals of design and analysis, New York, John Wiley and Sons, 2012. 216 p.

[2] Voropai N.I., Stennikov V.A. "Integrated intelligent energy systems", in Proceedings of the Russian Academy of Sciences - Energetics, 2014, vol. 1, pp.64-78 [Integrirovannie intellektualnie energeticheskie sistemy in Izvestia RAN. Energetika, 2014, vol. 1, pp.64-78] (in Russian)

[3] "On approval of the activity plan of the Ministry of Energy of the Russian Federation for the period 2019-2024", decree №45 dated 28.01.2019, 2018. Available at https://minenergo.gov.ru/view-pdf/13623/92908 (acceseed 15.03.2019) [Ob utverzhdenii plana deyatel'nosti Ministerstva energetiki Rossiyskoy Federatsii na period 2019-2024 godov: prikaz ot 28.01.2019 №45]

[4] Passport of the national program "Digital Economy of the Russian Federation", protocol dated 24.12.2018 №16, 2018. Available 
http://static.government.ru/media/files/urKHm0gTPPnzJlaKw 3M5cNLo6gczMkPF.pdf (accessed 17.03.2019) [Pasport natsional'noy programmy «Tsifrovaya ekonomika Rossiyskoy Federatsii» : protokol ot 24.12.2018 №16]

[5] Massel L.V., Arshinsky V.L., Massel A.G. "Intelligent computing on the basis of cognitive and event modeling and its application in energy security studies", in Renewable and Alternative Energy: Concept, Methodologies, Tools, and Applications. 2016. Pp. 780-787

[6] Tarasov V. B. "System-organizational approach in artificial intelligence", in Software and systems, 1999 , vol.3 pp. 6-13 ["Sistemno-organizacionnyj podhod v iskusstvennom intellekte" in Programmnye produkty i sistemy, 1999, vol.3 pp. 6-13] (in Russian)

[7] "Reducing the risks of cascading accidents in power systems", ed. Voropai N.I., Russian Academy Of Sciences, Siberian Branch, ESI SB RAS, Novosibirsk, Siberian Branch of Russian Academy of Sciences publishing, 2011, 303 p. [Snizheniye riskov kaskadnykh avariy $\mathrm{v}$ elektroenergeticheskikh sistemakh / otv. red. N.I. Voropay; Ros. akad. nauk, Sib. otd-niye, In-t sistem energetiki im. L.A. Melent'yeva [i dr.]. - Novosibirsk: Izd-vo SO RAN, 2011, 303 p.] (in Russian).

[8] V. I. Galperov Methods, models and algorithms for creaing multiagent systems in energy sector (based on example of task for energy systems state assessment). Cand. dis. (Tech.), Irkutsk, 2017. [Metody, modeli i algoritmy postroeniya mnogoagentnyh sistem $\mathrm{v}$ ehnergetike na primere zadachi ocenivaniya sostoyaniya ehlektroehnergeticheskih system: dis. kand. tekhn. nauk., Irkutsk, 2017]. (in Russian)

[9] L V. Massel. "Creation problems of intelligent systems of semiotic type for strategic contingency management in critical infrastructures ", in Information and mathematical technologies in science and management. 2016, vol. 1, pp.727. ["Problemi sozdaniya intellektualnikh sistem semioticheskogo tipa dlya strategischeskogo situatsionnogo upravleniya v kriticheskikh infrastrukturakh" in Informatsionnie i matematicheskie tehnologii $\mathrm{v}$ nauke $\mathrm{i}$ upravlenii] (in Russian). 